Dr. / Prof. Jian-bin Zheng

Institute of Analytical Science

Northwest University,

Xi'an 710069,

P.R.China.

E-mail zhengjb@nwu.edu.cn

Fax: +86-29-88303448(O)

Tel: 86-29-88302077(L)

June 27, 2016

“JELECHEM-D-16-00439"

Dear Mr. Editor,

Thank you very much for your letter of May 30, 2016, with regard to our manuscript (JELECHEM-D-16-00439) together with the comments from three reviewers. The manuscript (JELECHEM-D-16-00439) is being submitted to the Special Issue for the 80th birthday of Professor Hong-Yuan Chen. We appreciate you very much to give us a chance to submit the revised manuscript. Overall, the comment has been fair, encouraging and constructive. We have learned much from it. We are submitting here the revised manuscript entitled "Synthesis of FeOOH@PDA-Ag nanocomposites and their application for electrochemical sensing of hydrogen peroxide" after a very careful revision based on the comments from the three reviewers. You will find that we have made all the necessary corrections in the resubmit manuscript according to your comments and the reviewers' suggestions.

Thank you very much again for your kindness and all you have done on our work.

Sincerely, Jian-bin Zheng

1 Dedicated to Professor Dr Hong-Yuan Chen on the occasion of his 80th birthday and in honour of his contributions to electroanalytical chemistry.

* Corresponding author. E-mail: zhengjb@nwu.edu.cn 


\title{
Synthesis of FeOOH@PDA-Ag nanocomposites and their application for electrochemical sensing of hydrogen peroxide $^{1}$
}

\author{
Ning Zhang ${ }^{\text {,a }}$, Qinglin Sheng, ${ }^{\text {a }}$, Yuanzhen Zhou ${ }^{\text {b }}$, Sheying Dong, ${ }^{\text {, }}$ and Jianbin Zheng*,a \\ a, Institute of Analytical Science, Shaanxi Provincial Key Laboratory of Electroanalytical \\ Chemistry, Northwest University, Xi'an, Shaanxi 710069, China \\ b, School of Science, Xi'an University of Architecture and Technology, Xi'an 710055, China
}

\begin{abstract}
A well-dispersed Ag nanoparticle (Ag NP) anchored on rod-like Ferric oxyhydroxide@polydopamine (FeOOH@PDA) electrocatalyst was achieved via in situ reduction at room temperature. The obtained FeOOH@PDA-Ag nanocomposites were used for fabricating a novel non-enzymatic $\mathrm{H}_{2} \mathrm{O}_{2}$ sensor. The relationship between the sensing interface material and the sensor performance was studied, and a new method for the detection of $\mathrm{H}_{2} \mathrm{O}_{2}$ was established. The composition and morphology of the nanocomposites were characterized by transmission electron microscopic (TEM), X-ray diffraction (XRD) and energy-dispersive X-ray spectroscopy (EDS), which indicated that large numbers of Ag NPs with a narrow size were uniformly distributed on the surface of FeOOH@PDA. The electrochemical investigation showed that the nanocomposites had excellent electrocatalytic property toward the reduction of $\mathrm{H}_{2} \mathrm{O}_{2}$, and the sensor displayed a linear response to $\mathrm{H}_{2} \mathrm{O}_{2}$ in the range of $7.5 \mu \mathrm{M}-18.8 \mathrm{mM}$ with a detection limit of $2.5 \mu \mathrm{M}$ at a signal-to-noise ratio of 3 and a sensitivity of $11.8 \mu \mathrm{AmM}^{-1} \mathrm{~cm}^{-2}$. Compared with other non-enzymatic $\mathrm{H}_{2} \mathrm{O}_{2}$ sensors, the linear range of this sensor improved one order of magnitude. Moreover, the good analytical performance, low cost and facile preparation method made this novel material a promising candidate for the development of effective non-enzymatic $\mathrm{H}_{2} \mathrm{O}_{2}$ sensor.
\end{abstract}

Keywords: Non-enzymatic sensor; Silver nanoparticles; Ferric oxyhydroxide; Polydopamine; Hydrogen peroxide

1 Dedicated to Professor Dr Hong-Yuan Chen on the occasion of his 80th birthday and in honour of his contributions to electroanalytical chemistry.

* Corresponding author. E-mail: zhengjb@nwu.edu.cn 


\section{Introduction}

Hydrogen peroxide $\left(\mathrm{H}_{2} \mathrm{O}_{2}\right)$ is an essential mediator in a wide variety of fields, from food, to pharmaceutical, to industrial, to environmental protection [1-4]. Therefore, the accurate and rapid detection of $\mathrm{H}_{2} \mathrm{O}_{2}$ is very important. Nowadays, a variety of technologies have been exploited to determine $\mathrm{H}_{2} \mathrm{O}_{2}$, including chromatography [5], chemiluminescence [6], titrimetry [7], and electrochemistry [8]. Electrochemical method is one of the most effective approaches for the determination of $\mathrm{H}_{2} \mathrm{O}_{2}$ due to its intrinsic merits, such as the low detection limit, sound reliability, and simple apparatus $[9,10]$. Moreover, enormous researchers were more interested in non-enzymatic sensors, which can be ascribed to that non-enzymatic sensors can overcome the disadvantages of enzymatic sensors, including the instability, tedious process and high-cost [11-15]. For example, Bai et al. [16] designed a novel non-enzymatic $\mathrm{H}_{2} \mathrm{O}_{2}$ sensor based on $\mathrm{Ag}-\mathrm{MnOOH}-\mathrm{GO}$ hybrids and the sensor exhibited a low detection limit and a wide linear range. Besides, Shang et al. [17] constructed a glass carbon electrode (GCE) modified with nitrogen-doped graphene-hollow AuPd nanoparticle hybrid films as a non-enzymatic sensor for $\mathrm{H}_{2} \mathrm{O}_{2}$, which exhibited excellent electrocatalytic properties.

In recent years, with the development of nanotechnology, various kinds of metal nanoparticles (NPs), such as Au NPs [18], Pt NPs [19], Ag NPs [20] and Pd NPs [21], have been widely developed to construct $\mathrm{H}_{2} \mathrm{O}_{2}$ sensors. Among these nanoparticles, Ag NPs have stirred up great research interest in their counterparts as a result of their own distinct advantages of good biocompatibility, low toxicity, higher conductivity and outstanding electrocatalytic activity [22]. For example, Welch et al. [23] found that the electrocatalytic reduction of $\mathrm{H}_{2} \mathrm{O}_{2}$ happened directly on the Ag NPs. Yang et al. [24] also reported a novel sensing platform for $\mathrm{H}_{2} \mathrm{O}_{2}$ based on immobilized Ag NPs with chitosan on a GCE. The modified electrode exhibited sensitive response toward $\mathrm{H}_{2} \mathrm{O}_{2}$. These previous researches showed that Ag nanoparticles exhibited remarkable catalytic performance to $\mathrm{H}_{2} \mathrm{O}_{2}$. However, the strong van der Waals force between $\mathrm{Ag}$ 
NPs easily lead to aggregations and further restrict their electrocatalytic ability towards $\mathrm{H}_{2} \mathrm{O}_{2}$ [25]. In order to improve this problem, a large amount of catalyst supports have been successfully developed, including NG, $\mathrm{SiO}_{2}, \mathrm{MnO}_{2}-\mathrm{MWCNTs}$ and MWCNT-GO [26-29].

Ferric oxyhydroxide $(\mathrm{FeOOH})$ has been extensively studied for use in many fields, including absorptions materials, lithium batteries and magnetic recording media materials, because of its low cost and unique physicochemical properties, which include high surface to volume ratio, controllable synthesis process and low toxicity [30-32]. In addition, polydopamine (PDA), as a biomimetic polymer and a surface modification agent, has drawn people's consuming attention [33]. It is well known that dopamine can self-polymerization to become PDA under mild conditions and form polymer coatings on the surface of various supports [34]. Because of its abundant active catechol and amine groups, PDA can be used as reductants and binding reagents [35]. For example, Ye et al. [36] synthesized polydopamine wrapping Ag/graphene (PDA-Ag-RGO) hybrid by a one-step and environment-friendly reduction route, which exhibited superior catalytic activity and stability in the oxidation reaction of hydroquinone to benzoquinone. Zhang et al. [37] developed a facile and effective method for the preparation of the Pt/PDA/RGO composites, and the as-prepared composites displayed high electrocatalytic activity toward the reduction of $\mathrm{H}_{2} \mathrm{O}_{2}$ and $\mathrm{O}_{2}$. It is generally known that hybrid nanomaterial may exhibit better performance than a single component. Therefore, it is reasonable to functionalize $\mathrm{FeOOH}$ with $\mathrm{PDA}$, which can increase the active sites and prohibit aggregations of Ag NPs. However, to the best of our knowledge, there are rare reports on the synthesis and application of FeOOH@PDA-Ag in electrocatalysis.

Herein, we present a facile and green approach to prepare FeOOH@PDA-Ag nanocomposites and then employ FeOOH@PDA-Ag nanocomposites to fabricate a non-enzymatic $\mathrm{H}_{2} \mathrm{O}_{2}$ sensor. The low cost and simple synthesis of the nanocomposites may probably enhance the application of the sensor in $\mathrm{H}_{2} \mathrm{O}_{2}$ detection. 


\section{Experimental}

\subsection{Reagents and Materials}

Iron(III) chloride hexahydrate $\left(\mathrm{FeCl}_{3} \cdot 6 \mathrm{H}_{2} \mathrm{O}\right)$, cetyltrimethylammonium bromide (CTAB), trihydroxymethyl aminomethane (Tris), 3-hydroxytyramine hydrochloride $(\mathrm{DA} \cdot \mathrm{HCl})$, silver nitrate $\left(\mathrm{AgNO}_{3}\right)$, hydrochloric acid $(\mathrm{HCl})(38 \%$, v/v aqueous solution), ammonia aqueous (25\%-28\%, v/v aqueous solution), ethanol (EtOH), Hydrogen peroxide (30\%, v/v aqueous solution) was purchased from Tianjin Tianli Chemistry Reagent Co., Ltd (Tianjin, China). Chitosan (CS, MW 5-6 $\times 10^{5},>90 \%$ deacetylation) was received from Shanghai Yuanju Biotechnology Co., Ltd (Shanghai, China). 0.1 M phosphate buffered saline (PBS, pH 7.2) was used as the supporting electrolyte.

\subsection{Apparatus and Electrochemical Measurements}

Transmission electron microscope (TEM) images were recorded by Tecnai $G^{2}$ F20 S-TWIN (FEI, USA). Surface elemental compositions of the nanocomposites were obtained by an Energy-dispersive X-ray spectrometer (EDS). X-ray diffraction (XRD) patterns were taken by D/MAX-3C (Rigaku, Japan). Electrochemical measurements were carried out in a conventional three-electrode electroanalysis system controlled by CHI 660 electrochemical workstation (Shanghai CH Instrument Co. Ltd., China). Glassy carbon electrodes (GCE, $3 \mathrm{~mm}$ in diameter) and modified GCE were used as working electrodes; saturated calomel electrode (SCE) and platinum wire were used as the reference electrode and counter electrode, respectively. All the electrochemical experiments were finished at room temperature $\left(25 \pm 2^{\circ} \mathrm{C}\right)$.

\subsection{Preparation of the Sensor}

\subsubsection{Synthesis of $\mathrm{FeOOH}$}

FeOOH were synthesized according to the previous method [38]. Iron(III) chloride hexahydrate $\left(\mathrm{FeCl}_{3} \cdot 6 \mathrm{H}_{2} \mathrm{O}, 4 \mathrm{mmol}\right)$ and cetyltrimethylammonium bromide $(\mathrm{CTAB}, 1.0 \mathrm{~g}$ ) were dissolved in $40 \mathrm{~mL}$ of distilled water with ultrasonic and stirring to form a homogeneous solution. Then the mixture was transferred into a Teflon-lined stainless steel autoclave and heated at $80^{\circ} \mathrm{C}$ for $12 \mathrm{~h}$. After the reaction was completed, 
the resulting yellow solid product was centrifuged, washed with distilled water for several times, and finally dried at room temperature $\left(25 \pm 2^{\circ} \mathrm{C}\right)$.

\subsubsection{Synthesis of FeOOH@PDA}

The FeOOH@PDA core/shell structure nanocomposites were prepared according to a previously reported method [39]. $20 \mathrm{mg}$ of the as-prepared $\mathrm{FeOOH}$ was dispersed in a mixture of $20 \mathrm{~mL}$ Tris $(\mathrm{pH} 8.5)$ and $40 \mathrm{~mL}$ ethanol with magnetic stirring. Subsequently, $15 \mathrm{~mL}$ of a DA- $\mathrm{HCl}$ aqueous solution $\left(0.67 \mathrm{mg} \mathrm{mL}^{-1}\right)$ was added under stirring. Then polymerization was started and allowed to proceed at room temperature for $24 \mathrm{~h}$ under continuous magnetic stirring. During the process, the mixture turned from yellow to olive due to the oxidation and polymerization of dopamine. After that, products were centrifuged, washed with distilled water and ethanol for several times, followed by drying in a vacuum oven at $40^{\circ} \mathrm{C}$

\subsubsection{Fabrication of FeOOH@PDA-Ag}

Preparation of FeOOH@PDA-Ag nanocomposites was according to Ref. [40]. Silver ammonia solution was freshly prepared by adding ammonia aqueous solution

( $2 \mathrm{wt} \%$ ) into $5 \mathrm{mg} \mathrm{mL}^{-1} \mathrm{AgNO}_{3}$ solution until brown precipitation was just dissolved. Then 10 mg FeOOH@PDA was added to $20 \mathrm{~mL}$ of silver ammonia solution with magnetic stirring for about $12 \mathrm{~h}$ at room temperature. Finally the products were collected by centrifugation, washed with distilled water and ethanol several times, and dried in a vacuum.

\subsubsection{Electrode Modification}

The GCE was prepared by a simple casting method. Before to use, GCE was polished with 1.0 and $0.3 \mu \mathrm{m}$ alumina powder to obtain mirror like surface, respectively. It was rinsed with doubly distilled water, followed by sonication in ethanol solution and doubly distilled water successively. Then, GCE was dried in a nitrogen stream. The composites $(1 \mathrm{mg})$ were dispersed into chitosan $(1 \mathrm{~mL}, 0.5 \%)$ and sonicated for about $30 \mathrm{~min}$ to form a uniform suspension. Subsequently, the suspension $(10 \mu \mathrm{L})$ of FeOOH@PDA-Ag was dropped onto the surface of GCE and then dried in air at room temperature $\left(25 \pm 2^{\circ} \mathrm{C}\right)$. 


\section{Results and discussion}

\subsection{Characterization of FeOOH@PDA-Ag Nanocomposites}

Scheme 1 shows the schematic representation for the preparation of FeOOH@PDA-Ag nanocomposites. We employed the rod-like $\mathrm{FeOOH}$ as heterogeneous catalyst supports and PDA served as a binding reagent and reductant. Firstly, The CTAB was used as templates for the synthesis of $\mathrm{FeOOH}$ nanorods via the hydrothermal method [38]. The whole hydrothermal process was based on the following:

$$
\begin{gathered}
\mathrm{Fe}^{3+}+6 \mathrm{H}_{2} \mathrm{O} \rightarrow\left[\mathrm{Fe}\left(\mathrm{H}_{2} \mathrm{O}\right)_{6}\right]^{3+} \\
{\left[\mathrm{Fe}\left(\mathrm{H}_{2} \mathrm{O}\right)_{6}\right]^{3+} \stackrel{\text { CTAB }}{\longrightarrow} \mathrm{FeOOH} \text { nanorods }+4 \mathrm{H}_{2} \mathrm{O}+3 \mathrm{H}^{+}}
\end{gathered}
$$

Then, The FeOOH were wrapped with a thin PDA layer through the ethanol-mediated oxidative method [39], which solved the disadvantage of fewer functional groups on the surface of FeOOH. Thus, the FeOOH@PDA nanocomposites with core/shell structure were obtained. Finally, with the help of these active catechol and amine groups, $\left[\mathrm{Ag}\left(\mathrm{NH}_{3}\right)_{2}\right]^{+}$could be effectively adsorbed onto the surface of the FeOOH@PDA and immediately in situ reduced to form Ag NPs [40].

As shown in Figure 1, the morphologies of $\mathrm{FeOOH,} \mathrm{FeOOH@PDA} \mathrm{and}$ FeOOH@PDA-Ag were characterized by TEM. From Figures 1A and D, it can be seen that $\mathrm{FeOOH}$ revealed rod-like structures and the average length of $\mathrm{FeOOH}$ was approximately $400 \mathrm{~nm}$ (aspect ratio $\approx 13$ ) with an average diameter of $30 \pm 5 \mathrm{~nm}$. From Figures 1B and E, it can be seen clearly that the thin PDA shell layers formed around the $\mathrm{FeOOH}$ cores with an average thickness about $2 \mathrm{~nm}$, which displayed a distinct core-shell structure. The PDA coating can not only prevent the FeOOH from aggregating but also functionalize the core materials. From Figures $1 \mathrm{C}$ and F, it can be seen obviously that the surfaces of the FeOOH@PDA nanocomposites existed some clearly dark spots, which indicated that Ag NPs had been successfully synthesized via a simple in situ reduction method. In addition, the small Ag NPs were densely and uniformly distributed on the FeOOH@PDA surface.

To further confirm the successful formation of FeOOH@PDA-Ag, analysis by 
XRD and EDS was carried out. Figure 2A showed the XRD diffraction patterns for the FeOOH, FeOOH@PDA and FeOOH@PDA-Ag. As shown in Figure 2A(a), the positions of all of the $\mathrm{FeOOH}$ peaks at $11.9^{\circ}, 26.8^{\circ}, 34.1^{\circ}, 35.2^{\circ}$ and $55.9^{\circ}$ were very closely matched with the (110), (310), (400), (211) and (521) planes corresponding to the reported values (JCPDS card No. 34-1266) of the $\beta$-FeOOH structure. However, no additional diffraction peaks were found in the FeOOH@PDA (Figure 2A(b)) since the PDA layer was thin and non-crystalline. Figure 2A(c) shows several characteristic peaks at $38.1^{\circ}, 64.4^{\circ}$ and $77.3^{\circ}$, which can be well indexed to (111), (220) and (311) planes of the face centered cubic phase of Ag (JCPDS card No. 04-0783). In addition, the composition of FeOOH@PDA-Ag was determined by EDS, it was found that the composite were composed of C, O, N, Fe and Ag elements (Figure 2B). These results indicated that FeOOH@PDA-Ag nanocomposites were successfully prepared.

To further analyze the surface state of the as-prepared nanocomposites, XPS was used to characterize the surface elemental components. As shown in Figure 3A, the XPS spectrum of FeOOH@PDA-Ag confirmed the existence of C, N, O, Ag and Fe elements. As shown in Figure 3B, The Fe2p consists of a Fe2 $\mathrm{p}_{3 / 2}$ peak centered at $710.9 \mathrm{eV}$ and a Fe2 $\mathrm{p}_{1 / 2}$ peak at $724.4 \mathrm{eV}$, which indicated the formation of $\beta-\mathrm{FeOOH}$ [41,42]. Figure 3C showed the high-resolution N1s XPS spectra and we can see that the peak of N1s located at $397.5 \mathrm{eV}$, which was consistent with the earlier report about PDA [43]. The typical Ag3d spectrum of FeOOH@PDA-Ag was shown in Figure 3D, the peaks of $\mathrm{Ag} 3 \mathrm{~d}_{5 / 2}$ and $\mathrm{Ag} 3 \mathrm{~d}_{3 / 2}$ can be observed at 366.0 and $371.9 \mathrm{e} \mathrm{V}$, respectively, which indicated that $\mathrm{Ag}$ is present in the metallic state [44]. It further indicated that FeOOH@PDA-Ag nanocomposites had been synthesized successfully.

\subsection{Electrochemical Properties of FeOOH@PDA-Ag Nanocomposites}

Cyclic voltammogram (CV) was used to investigate the electrocatalytic activity of modified electrodes toward $\mathrm{H}_{2} \mathrm{O}_{2}$ as shown in Figure 4. In $\mathrm{N}_{2}$-saturated 0.1 M PBS (pH 7.2), the bare GCE (curve a), FeOOH/GCE (curve b), FeOOH@PDA/GCE (curve c) and FeOOH@PDA-Ag/GCE (curve d) exhibited almost no electrochemical response in the absence of $\mathrm{H}_{2} \mathrm{O}_{2}$ at the scan rate of $100 \mathrm{mV} / \mathrm{s}$. However, after adding $2.5 \mathrm{mM} \mathrm{H}_{2} \mathrm{O}_{2}$, We can see that FeOOH@PDA-Ag/GCE (curve h) showed a 
remarkable catalytic current peak about $41 \mu \mathrm{A}$ in intensity at $-0.54 \mathrm{~V}$. In comparison with bare GCE (curve e), FeOOH/GCE (curve f) and FeOOH@PDA/GCE (curve g), the catalytic peak current of FeOOH@PDA-Ag/GCE was increased obviously. The study revealed that the FeOOH@PDA-Ag nanocomposites exhibited a notable catalytic performance for $\mathrm{H}_{2} \mathrm{O}_{2}$ reduction. With the introduction of $\mathrm{Ag}$ NPs, the electron-transfer reactivity for the detection of $\mathrm{H}_{2} \mathrm{O}_{2}$ could be greatly enhanced [45, 46]. Besides, the increased electrocatalytic property could be ascribed to the function of $\mathrm{FeOOH}$ with PDA, which provides a high surface-to-volume ratio and more active sites for the immobilization of Ag NPs.

The catalytic activity of FeOOH@PDA-Ag/GCE by changing the concentration of $\mathrm{H}_{2} \mathrm{O}_{2}$ is shown in Figure 5A. We can see that no characteristic peak was shown in the absence of $\mathrm{H}_{2} \mathrm{O}_{2}$. However, it is worthwhile to note that the reduction current appeared and gradually increased with the addition of $\mathrm{H}_{2} \mathrm{O}_{2}$ into the $\mathrm{N}_{2}$-saturated 0.1 M PBS (pH 7.2). From the inset of Figure 5A, we can discover that the peak current increased linearly with the concentration of $\mathrm{H}_{2} \mathrm{O}_{2}$ in the range of $0-5.0 \mathrm{mM}$. The above results indicated that the FeOOH@PDA-Ag nanocomposite had good electrocatalytic activity towards $\mathrm{H}_{2} \mathrm{O}_{2}$. Figure $5 \mathrm{~B}$ displays the $\mathrm{CV}$ curves of the FeOOH@PDA-Ag/GCE under different scan rates. From the experimental results we can see that the cathodic peak current increased distinctly with increasing the scan rates from 20 to $200 \mathrm{mV} / \mathrm{s}$. As shown in the inset of Figure 5B, the cathodic peak current increased in a linear relationship with the square root of scan rates in the range of $20-200 \mathrm{mV} / \mathrm{s}$, indicating that the process is diffusion-controlled.

Figure 6A shows the amperometric response curve of FeOOH@PDA-Ag/GCE in $\mathrm{N}_{2}$-saturated 0.1 M PBS ( $\mathrm{pH}$ 7.2) for different concentrations of $\mathrm{H}_{2} \mathrm{O}_{2}$ at $-0.2 \mathrm{~V}$. Although it exhibited the biggest response current at the electric potential of $-0.54 \mathrm{~V}$, we chose the potential of $-0.2 \mathrm{~V}$ as the work potential in consideration of anti-interference. such a potential can ensure a lower background, good signal-to-noise ratio and less interference of other electroactive species in the solution [16]. In Figure 6B, a linear response range of $7.5 \mu \mathrm{M}-18.8 \mathrm{mM}$ (linear equation: $\left.\mathrm{I}_{\mathrm{p}}(\mu \mathrm{A})=0.00446-0.8321 \cdot \mathrm{C}(\mathrm{mM}) \quad(\mathrm{R}=0.9991)\right)$ was obtained. When the 
concentration of $\mathrm{H}_{2} \mathrm{O}_{2}$ is above $18.8 \mathrm{mM}$, the amperometric responses gradually reach to saturation, because the electrode surface partially covered by the adsorbed reaction intermediates cannot offer sufficient sites to accommodate the incoming $\mathrm{H}_{2} \mathrm{O}_{2}$ [47]. It was obviously that the amperometric current response reached a stable value within 3 $\mathrm{s}$, indicating a fast response behavior. The detection limit was $2.5 \mu \mathrm{M}(\mathrm{S} / \mathrm{N}=3)$, and the sensitivity was estimated to be $11.8 \mu \mathrm{A} \mathrm{mM}^{-1} \mathrm{~cm}^{-2}$.

Several typical non-enzymatic $\mathrm{H}_{2} \mathrm{O}_{2}$ sensors are listed in Table 1. Compared with these sensors, the present modified GCE had a wider linear range. It may be due to the functionalization of $\mathrm{FeOOH}$ with PDA, which has some advantages such as more active sites and larger surface area. Thus, FeOOH@PDA can successfully attach more Ag NPs to provide a good platform for $\mathrm{H}_{2} \mathrm{O}_{2}$ adsorption and reaction. Therefore, FeOOH@PDA-Ag nanocomposites exhibited a notable catalytic performance for $\mathrm{H}_{2} \mathrm{O}_{2}$ reduction.

\subsection{Interference Study}

Some common interfering substances such as ascorbic acid (AA), uric acid (UA) and D-glucose (D-Glu), may affect the sensor responses. As is shown in Figure 7, in the $\mathrm{N}_{2}$-saturated $0.1 \quad \mathrm{M} \quad \mathrm{PBS} \quad(\mathrm{pH}$ 7.2), the amperometric responses of FeOOH@PDA-Ag/GCE to the consecutive injection of $\mathrm{H}_{2} \mathrm{O}_{2}(0.05 \mathrm{mM})$ and interferents $(0.05 \mathrm{mM})$ were studied at a working potential of $-0.2 \mathrm{~V}$. It could be seen clearly that an obvious amperometric response appeared after injecting of $0.05 \mathrm{mM}$ $\mathrm{H}_{2} \mathrm{O}_{2}$ into the 0.1 M PBS ( $\mathrm{pH}$ 7.2). However, the amperometric response did not changed when adding AA, D-Glu and UA, indicating that FeOOH@PDA-Ag/GCE exhibited good anti-interference ability to electroactive species, which was attributed to the relatively lower potential at $-0.2 \mathrm{~V}$.

\subsection{Repeatability and Stability}

The repeatability and stability of FeOOH@PDA-Ag/GCE were also evaluated. The repeatability was examined at five different modified electrodes prepared in the same conditions and the relative standard deviation (RSD) was less than $4 \%$, which indicated that FeOOH@PDA-Ag nanocomposites were highly reproducible. Besides, the modified electrode remained $90 \%$ of its initial current response after two weeks. 
Thus, the FeOOH@PDA-Ag/GCE possessed acceptable repeatability and stability.

\section{Conclusions}

In summary, FeOOH@PDA-Ag nanocomposites with core/shell structure have been successfully synthesized and the non-enzymatic $\mathrm{H}_{2} \mathrm{O}_{2}$ sensor based on the nanocomposites was fabricated. This sensor exhibited several advantages, including wide linearity, simple fabrication, fast response and good selectivity. Considering the facile and environmental friendly preparation route and excellent electrocatalytic ability of FeOOH@PDA-Ag nanocomposites, the present study may provide a feasible method to develop new electrochemical sensors.

\section{Acknowledgments}

The authors gratefully acknowledge the financial support of this project by the National Science Foundation of China (21575113, 21275116 and 21105080), Specialized Research Fund for the Doctoral Program of Higher Education (No. 20126101120023), the Natural Science Foundation of Shaanxi Province in China (2013KJXX-25), and the Scientific Research Foundation of Shaanxi Provincial Key Laboratory (13JS097, 13JS098, 14JS094, 15JS100). 


\section{References}

[1] P. Kanyong, S. Rawlinson, J. Davis, A non-enzymatic sensor based on the redox of ferrocene carboxylic acid on ionic liquid film-modified screen-printed graphite electrode for the analysis of hydrogen peroxide residues in milk, J. Electroanal. Chem. 766 (2016) 147-151.

[2] J. Bai, X. Jiang, A facile one-pot synthesis of copper sulfide-decorated reduced graphene oxide composites for enhanced detecting of $\mathrm{H}_{2} \mathrm{O}_{2}$ in biological environments, Anal. Chem. 85 (2013) 8095-8101.

[3] M. Mathew, N. Sandhyarani, A novel electrochemical sensor surface for the detection of hydrogen peroxide using cyclic bisureas/gold nanoparticle composite, Biosens. Bioelectron. 28 (2011) 210-215.

[4] R.C. Matos, J.J. Pedrotti, L. Angnes, Flow-injection system with enzyme reactor for differential amperometric determination of hydrogen peroxide in rainwater, Anal. Chim. Acta 441 (2011) 73-79.

[5] U. Pinkernell, S. Effkemann, U. Karst, Simultaneous HPLC determination of peroxyacetic acid and hydrogen peroxide, Anal. Chem. 69 (1997) 3623-3627.

[6] H. Jin, D.A. Heller, M. Kalbacova, J.H. Kim, J.Q. Zhang, A.A. Boghossian, N. Maheshri, M.S. Strano, Detection of single-molecule $\mathrm{H}_{2} \mathrm{O}_{2}$ signalling from epidermal growth factor receptor using fluorescent single-walled carbon nanotubes, Nat. Nanotechnol. 5 (2010) 302-309.

[7] N.V. Klassen, D. Marchington, H.C.E. McGowan, $\mathrm{H}_{2} \mathrm{O}_{2}$ determination by the $\mathrm{I}_{3}$ method and by $\mathrm{KMnO}_{4}$ titration, Anal. Chem. 66 (1994) 2921-2925.

[8] M.M. Liu, R. Liu, W. Chen, Graphene wrapped $\mathrm{Cu}_{2} \mathrm{O}$ nanocubes: non-enzymatic electrochemical sensors for the detection of glucose and hydrogen peroxide with enhanced stability, Biosens. Bioelectron. 45 (2013) 206-212.

[9] D. Moscone, D. D'ottavi, D. Compagnone, G. Palleschi, Construction and analytical characterization of Prussian blue-based carbon paste electrodes and their assembly as oxidase enzyme sensors, Anal. Chem. 73 (2001) 2529-2535.

[10] F.N. Xi, D.J. Zhao, X.W. Wang, P. Chen, Non-enzymatic detection of hydrogen 
peroxide using a functionalized three-dimensional graphene electrode, Electrochem. Commun. 26 (2013) 81-84.

[11] J.P. Li, Y.P. Li, Y. Zhang, G. Wei, Highly sensitive molecularly imprinted electrochemical sensor based on the double amplification by an inorganic prussian blue catalytic polymer and the enzymatic effect of glucose oxidase, Anal. Chem. 84 (2012) 1888-1893.

[12] J.H. Lin, L.J. Zhang, S.S. Zhang, Amperometric biosensor based on coentrapment of enzyme and mediator by gold nanoparticles on indium-tin oxide electrode, Anal. Biochem. 370 (2007) 180-185.

[13] K.K. Lee, P.Y. Loh, C.H. Sow, W.S. Chin, CoOOH nanosheet electrodes: simple fabrication for sensitive electrochemical sensing of hydrogen peroxide and hydrazine, Biosens. Bioelectron. 39 (2013) 255-260.

[14] Y.X. Fang, D. Zhang, X. Qin, Z.Y. Miao, S. Takahashi, J. Anzai, Q. Chen, A non-enzymatic hydrogen peroxide sensor based on poly (vinyl alcohol)-multiwalled carbon nanotubes-platinum nanoparticles hybrids modified glassy carbon electrode, Electrochim. Acta 70 (2012) 266-271.

[15] Y.P. Lin, X. Chen, Y.X. Lin, Q. Zhou, D.P. Tang, Non-enzymatic sensing of hydrogen peroxide using a glassy carbon electrode modified with a nanocomposite made from carbon nanotubes and molybdenum disulfide, Microchim. Acta 182 (2015) 1803-1809.

[16] W.S. Bai, F. Nie, J.B. Zheng, Q.L. Sheng, Novel silver nanoparticle-manganese oxyhydroxide-graphene oxide nanocomposite prepared by modified silver mirror reaction and its application for electrochemical sensing, ACS Appl. Mater. Inter. 6 (2014) 5439-5449.

[17] L. Shang, B.Z. Zeng, F.Q. Zhao, Fabrication of Novel Nitrogen-Doped Graphene-Hollow AuPd Nanoparticle Hybrid Films for the Highly Efficient Electrocatalytic Reduction of $\mathrm{H}_{2} \mathrm{O}_{2}$, ACS Appl. Mater. Inter. 7 (2014) 122-128.

[18] N.M. Jia, B.Z. Huang, L.N. Chen, L. Tan, S.Z. Yao, A simple non-enzymatic hydrogen peroxide sensor using gold nanoparticles-graphene-chitosan modified electrode, Sens. Actuators, B-Chem. 195 (2014) 165-170. 
[19] Y. Yang, R.Z. Fu, J.J. Yuan, S.Y. Wu, J.L. Zhang, H.Y. Wang, Highly sensitive hydrogen peroxide sensor based on a glassy carbon electrode modified with platinum nanoparticles on carbon nanofiber heterostructures, Microchim. Acta 182 (2015) 2241-2249.

[20] M.K. Kundu, M. Sadhukhan, S. Barman, Ordered assemblies of silver nanoparticles on carbon nitride sheets and their application in the non-enzymatic sensing of hydrogen peroxide and glucose, J. Mater. Chem. B 3 (2015) 1289-1300.

[21] J. Wang, H.B. Sun, H.Y. Pan, Y.Y. Ding, J.G. Wan, G.H. Wang, M. Han, Detection of hydrogen peroxide at a palladium nanoparticle-bilayer graphene hybrid-modified electrode, Sens. Actuators, B-Chem. 230 (2016) 690-696.

[22] W.S. Bai, Q.L. Sheng, X.Y. Ma, J.B. Zheng, Synthesis of silver nanoparticles based on hydrophobic interface regulation and its application of electrochemical catalysis, ACS Sustain. Chem. Eng. 3 (2015) 1600-1609.

[23] C.M. Welch, C.E. Banks, A.O. Simm, R.G. Compton, Silver nanoparticle assemblies supported on glassy-carbon electrodes for the electro-analytical detection of hydrogen peroxide, Anal. Bioanal. Chem. 382 (2005) 12-21.

[24] Z.Y. Yang, C.C. Qi, X.H. Zheng, J.B. Zheng, Synthesis of silver nanoparticle at a gas/liquid interface in the presence of silver seeds and its application for electrochemical sensing, Talanta 140 (2015) 198-203.

[25] C.Y. Liu, J.M. Hu, Hydrogen peroxide biosensor based on the direct electrochemistry of myoglobin immobilized on silver nanoparticles doped carbon nanotubes film, Biosens. Bioelectron. 24 (2009) 2149-2154.

[26] M.T. Tajabadi, W.J. Basirun, F. Lorestani, R. Zakaria, S. Baradaran, Y.M. Amin, M.R. Mahmoudian, M. Rezayi, M. Sookhakian, Nitrogen-doped graphene-silver nanodendrites for the non-enzymatic detection of hydrogen peroxide, Electrochim. Acta 151 (2015) 126-133.

[27] C. Liu, J.S. Li, J. Wang, J.W. Qi, W.H. Fan, J.Y. Shen, X.Y. Sun, W.Q. Han, L.J. Wang, Synthesis of $\mathrm{Ag} @ \mathrm{SiO}_{2}$ yolk-shell nanoparticles for hydrogen peroxide detection, RSC Adv. 5 (2015) 17372-17378. 
[28] Y. Han, J.B. Zheng, S.Y. Dong, A novel nonenzymatic hydrogen peroxide sensor based on $\mathrm{Ag}-\mathrm{MnO}_{2}-\mathrm{MWCNTs}$ nanocomposites, Electrochim. Acta 90 (2013) $35-43$.

[29] F. Lorestani, Z. Shahnavaz, P. Mn, Y. Alias, N.S.A. Manan, One-step hydrothermal green synthesis of silver nanoparticle-carbon nanotube reduced-graphene oxide composite and its application as hydrogen peroxide sensor, Sens. Actuators, B-Chem. 208 (2015) 389-398.

[30] X.Y. Zhang, J. Ge, B. Lei, Y.M. Xue, Y.P. Du, High quality $\beta-F e O O H$ nanostructures constructed by a biomolecule-assisted hydrothermal approach and their pH-responsive drug delivery behaviors, CrystEngComm 17 (2015) 4064-4069.

[31] G. Wirnsberger, K. Gatterer, H.P. Fritzer, W. Grogger, B. Pillep, P. Behrens, M.F. Hansen, C.B. Koch, Mesostructured iron oxyhydroxides. 1. Synthesis, local structure, and magnetism, Chem. Mater. 13 (2001) 1453-1466.

[32] X.L. Fang, Y. Li, C. Chen, Q. Kuang, X.Z. Gao, Z.X. Xie, S.Y. Xie, R.B. Huang, L.S. Zheng, pH-induced simultaneous synthesis and self-assembly of 3D layered $\beta$-FeOOH nanorods, Langmuir 26 (2009) 2745-2750.

[33] L.Q. Guo, Q. Liu, G.L. Li, J.B. Shi, J.Y. Liu, T.Wang, G.B. Jiang, A mussel-inspired polydopamine coating as a versatile platform for the in situ synthesis of graphene-based nanocomposites, Nanoscale 4 (2012) 5864-5867.

[34] M. Zhang, X.W. He, L.X. Chen, Y.K. Zhang, Preparation of IDA-Cu functionalized core-satellite $\mathrm{Fe}_{3} \mathrm{O}_{4}$ /polydopamine/Au magnetic nanocomposites and their application for depletion of abundant protein in bovine blood, J. Mater. Chem. 20 (2010) 10696-10704.

[35] C.J. Wu, G.X. Zhang, T. Xia, Z.N. Li, K. Zhao, Z.W. Deng, D.Z. Guo, B. Peng, Bioinspired synthesis of polydopamine/Ag nanocomposite particles with antibacterial activities, Mat. Sci. C-Mater. 55 (2015) 155-165.

[36] W.C. Ye, X.Z. Shi, J. Su, Y. Chen, J.J. Fu, X.J. Zhao, F. Zhou, C.M. Wang, D.S. Xue, One-step reduction and functionalization protocol to synthesize polydopamine wrapping Ag/graphene hybrid for efficient oxidation of 
hydroquinone to benzoquinone, Appl. Catal. B-Environ. 160 (2014) 400-407.

[37] Q.L. Zhang, T.Q. Xu, J. Wei, J.R. Chen, A.J. Wang, J.J. Feng, Facile synthesis of uniform Pt nanoparticles on polydopamine-reduced graphene oxide and their electrochemical sensing, Electrochim. Acta 112 (2013) 127-132.

[38] X. Wang, X.Y. Chen, L.S. Gao, H.G. Zheng, M.R. Ji, C.M. Tang, T. Shen, Z.D. Zhang, Synthesis of $\beta-\mathrm{FeOOH}$ and $\alpha-\mathrm{Fe}_{2} \mathrm{O}_{3}$ nanorods and electrochemical properties of $\beta$-FeOOH, J. Mater. Chem. 14 (2004) 905-907.

[39] Y. Mao, W.Q. Jiang, S.H. Xuan, Q.L. Fang, K.C.F. Leung, B.S. Ong, S. Wang, X.L. Gong, Rod-like $\beta$-FeOOH@ poly (dopamine)-Au-poly (dopamine) nanocatalysts with improved recyclable activities, Dalton Trans. 44 (2015) 9538-9544.

[40] Y.J. Xie, B. Yan, H.L. Xu, J. Chen, Q.X. Liu, Y.H. Deng, H.B. Zeng, Highly regenerable mussel-inspired $\mathrm{Fe}_{3} \mathrm{O}_{4} @$ polydopamine-Ag core-shell microspheres as catalyst and adsorbent for methylene blue removal, ACS Appl. Mater. Inter. 6 (2014) 8845-8852.

[41] Y.X. Zhang, Y. Jia, A facile solution approach for the synthesis of akaganéite $(\beta-\mathrm{FeOOH})$ nanorods and their ion-exchange mechanism toward As (V) ions, Applied Surface Science 290 (2014) 102-106.

[42] L.F. Chen, Z.Y. Yu, J.J. Wang, Q.X. Li, Z.Q. Tan, Y.W. Zhu, S.H. Yu, Metal-like fluorine-doped $\beta$-FeOOH nanorods grown on carbon cloth for scalable high-performance supercapacitors, Nano Energy 11 (2015) 119-128.

[43] H.Y. Liu, P.X. Xi, G.Q. Xie, Y.J. Shi, F.P. Hou, L. Huang, F.J. Chen, Z.Z. Zeng, C.W. Shao, J. Wang, Simultaneous reduction and surface functionalization of graphene oxide for hydroxyapatite mineralization, The Journal of Physical Chemistry C 116 (2012) 3334-3341.

[44] D.L. Zhou, D.J. Chen, P.P. Zhang, F.F. Li, J.R. Chen, A.J. Wang, J.J. Feng, Facile synthesis of $\mathrm{MnO} 2-\mathrm{Ag}$ hollow microspheres with sheet-like subunits and their catalytic properties, CrystEngComm 16 (2014) 863-869.

[45] M. Honda, T. Kodera, H. Kita, Electrochemical behavior of $\mathrm{H}_{2} \mathrm{O}_{2}$ at $\mathrm{Ag}$ in $\mathrm{HClO}_{4}$ aqueous solution, Electrochim. Acta 31 (1986) 377-383. 
[46] X. Gan, T. Liu, J. Zhong, X.J. Liu, G.X. Li, Effect of silver nanoparticles on the electron transfer reactivity and the catalytic activity of myoglobin, ChemBioChem 5 (2004) 1686-1691.

[47] X.H. Niu, M.B. Lan, H.L. Zhao, C. Chen, Highly sensitive and selective nonenzymatic detection of glucose using three-dimensional porous nickel nanostructures, Anal. Chem. 85 (2013) 3561-3569.

[48] W.B. Lu, F. Liao , Y.L. Luo, G.H. Chang, X.P. Sun, Hydrothermal synthesis of well-stable silver nanoparticles and their application for enzymeless hydrogen peroxide detection, Electrochim. Acta 56 (2011) 2295-2298.

[49] Y.H. Wang, X.J. Yang, J. Bai, X. Jiang, G.Y. Fan, High sensitivity hydrogen peroxide and hydrazine sensor based on silver nanocubes with rich $\{100\}$ facets as an enhanced electrochemical sensing platform, Biosens. Bioelectron. 43 (2013) 180-185.

[50] J. Zhang, J.B. Zheng, An enzyme-free hydrogen peroxide sensor based on $\mathrm{Ag} / \mathrm{FeOOH}$ nanocomposites, Anal. Methods 7 (2015) 1788-1793.

[51] Y. Tian, F.L. Wang, Y.X. Liu, F. Pang, X. Zhang, Green synthesis of silver nanoparticles on nitrogen-doped graphene for hydrogen peroxide detection, Electrochim. Acta 146 (2014) 646-653.

[52] Z.P. Wu, S.W. Yang, Z. Chen, T.T. Zhang, T.T. Guo, Z.F. Wang, F. Liao, Synthesis of Ag nanoparticles-decorated poly (m-phenylenediamine) hollow spheres and the application for hydrogen peroxide detection, Electrochim. Acta 98 (2013) 104-108.

[53] X.J. Yang, Y.H. Wang, Y.W. Liu, X. Jiang, A sensitive hydrogen peroxide and glucose biosensor based on gold/silver core-shell nanorods, Electrochim. Acta 108 (2013) 39-44. 


\section{Figure Caption}

Scheme 1. The synthesis route of FeOOH@PDA-Ag nanocomposites.

Figure 1. TEM images of nanocomposites: (A, D) FeOOH, (B, E) FeOOH@PDA, (C, F) FeOOH@PDA-Ag.

Figure 2. (A) XRD diffraction patterns of (a) $\mathrm{FeOOH,} \mathrm{(b)} \mathrm{FeOOH} @ \mathrm{PDA}$ and (c) FeOOH@PDA-Ag nanocomposites. (B) EDS spectrum of FeOOH@PDA-Ag nanocomposites.

Figure 3. XPS survey spectrum (A), narrow spectrum of Fe2p (B), N1s (C) and Ag3d (D) of the FeOOH@PDA-Ag nanocomposites.

Figure 4. $\mathrm{CVs}$ of $\mathrm{H}_{2} \mathrm{O}_{2}$ obtained by (a, e) bare GCE, (b, f) $\mathrm{FeOOH} / \mathrm{GCE}$, (c, g) FeOOH@PDA/GCE and (d, h) FeOOH@PDA-Ag/GCE in $\mathrm{N}_{2}$-saturated 0.1 M PBS (pH 7.2) in the absence (A) and presence (B) of $2.5 \mathrm{mM} \mathrm{H}_{2} \mathrm{O}_{2}$ at a scan rate of $100 \mathrm{~m} \mathrm{~V} / \mathrm{s}$.

Figure 5. (A) CVs of $\mathrm{H}_{2} \mathrm{O}_{2}$ obtained by FeOOH@PDA-Ag/GCE in $\mathrm{N}_{2}$-saturated $0.1 \mathrm{M}$ PBS (pH 7.2) (concentrations of $\mathrm{H}_{2} \mathrm{O}_{2}$ from a to $\mathrm{k}: 0,0.5,1,1.5,2,2.5,3,3.5,4,4.5$ and $5.0 \mathrm{mM}$ ) at a scan rate of $100 \mathrm{~m} \mathrm{~V} / \mathrm{s}$. Inset: Linear fitting program of the electrocatalytic peak currents of $\mathrm{H}_{2} \mathrm{O}_{2}$

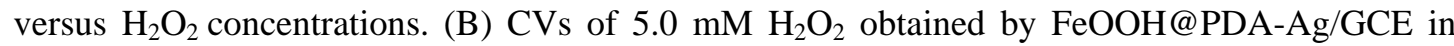
$\mathrm{N}_{2}$-saturated 0.1 M PBS ( $\mathrm{pH} 7.2$ ) at various scan rates (from a to $\mathrm{j}: 20,40,60,80,100,120,140$, $160,180$, and $200 \mathrm{~m} \mathrm{~V} / \mathrm{s})$. Inset: Linear fitting program of the electrocatalytic peak currents of $\mathrm{H}_{2} \mathrm{O}_{2}$ versus the square root of scan rate.

Figure 6. (A) Amperometric response of $\mathrm{H}_{2} \mathrm{O}_{2}$ obtained by FeOOH@PDA-Ag/GCE at $-0.2 \mathrm{~V}$ vs SCE in $\mathrm{N}_{2}$-saturated 0.1 M PBS (pH 7.2). (B) Plot of response current versus $\mathrm{H}_{2} \mathrm{O}_{2}$ concentration.

Figure 7. Amperometric response of $0.05 \mathrm{mM} \mathrm{H} \mathrm{H}_{2} \mathrm{O}_{2}, A A$, D-Glucose and UA at FeOOH@PDA-Ag/GCE. 
Table 1.

The comparison of seven $\mathrm{H}_{2} \mathrm{O}_{2}$ sensors

\begin{tabular}{cccccc}
\hline Sensors & $\begin{array}{c}\text { Applied } \\
\text { potential } \\
(\mathrm{V})\end{array}$ & $\begin{array}{c}\text { Linear range } \\
(\mathrm{mM})\end{array}$ & $\begin{array}{c}\text { Sensitivity } \\
\left(\mu \mathrm{A} \mathrm{mM}^{-1} \mathrm{~cm}^{-2}\right)\end{array}$ & $\begin{array}{c}\text { detection } \\
\text { limit } \\
(\mu \mathrm{M})\end{array}$ & References \\
\hline PQ11-Ag NPs/GCE & -0.3 & $0.1-180$ & - & 33.9 & {$[48]$} \\
PVP-Ag NCs/GCE & -0.3 & $0.05-70$ & - & 0.18 & {$[49]$} \\
FeOOH/Ag/PGE & -0.2 & $0.03-15$ & 8.07 & 22.8 & {$[50]$} \\
Ag NPs/N-G/GCE & -0.3 & $0.1-126.4$ & 44.6 & 1.2 & {$[51]$} \\
Ag NP-Pm PD/GCE & -0.9 & $0.1-10$ & - & 0.88 & {$[52]$} \\
Au@AgNRs/GCE & -0.3 & $0.02-7.02$ & - & 0.67 & {$[53]$} \\
FeOOH@/PDA-Ag/GCE & -0.2 & $0.0075-18.8$ & 11.8 & 2.5 & This work \\
\hline
\end{tabular}


Scheme 1

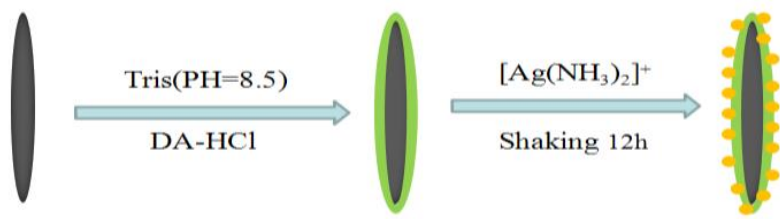

$$
\begin{aligned}
& \bigcap \mathrm{FeOOH} \quad \int \text { poly(dopamine) } \quad \text { Ag NPs }
\end{aligned}
$$

\section{Scheme 1}




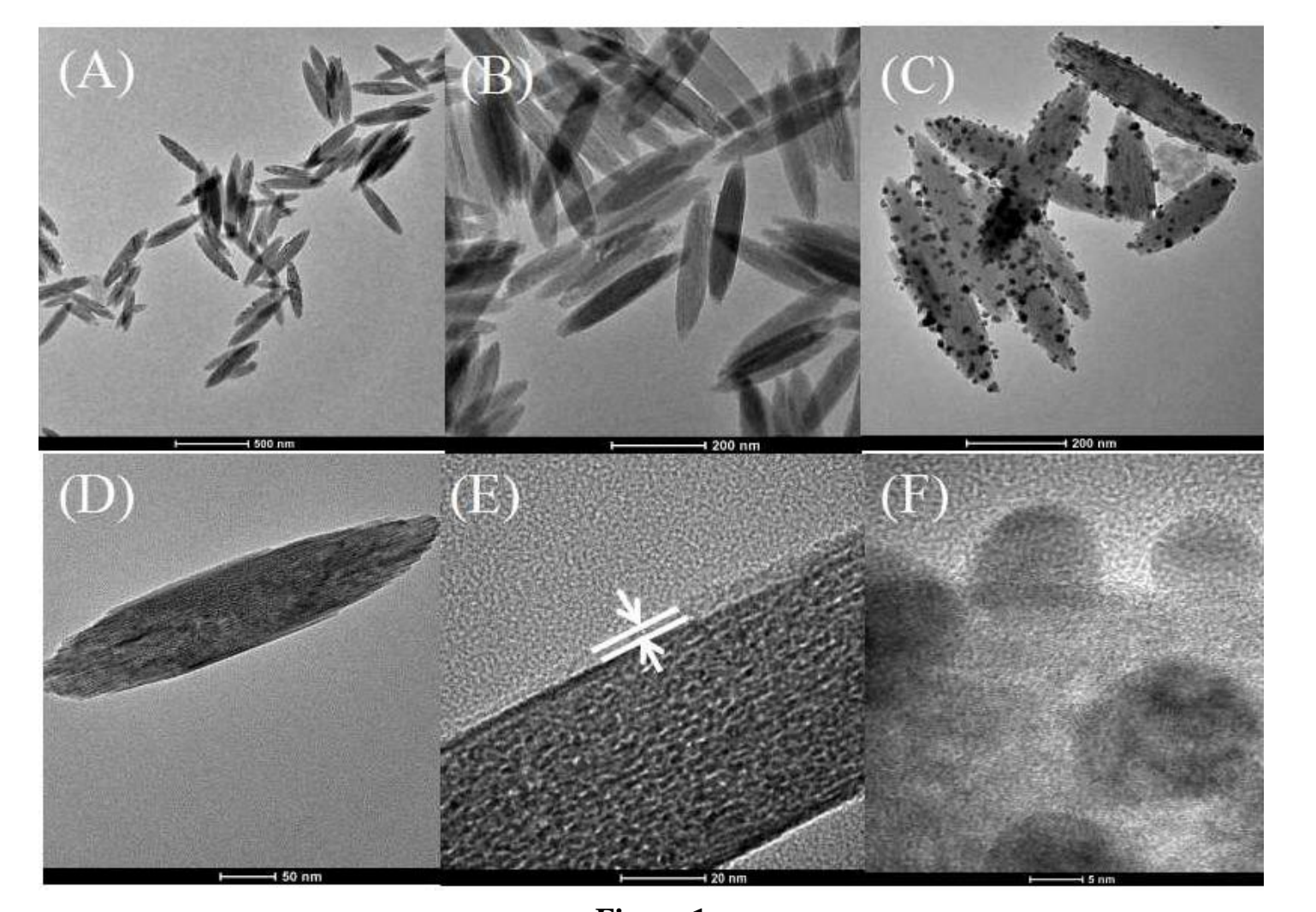

Figure 1

Figure 1
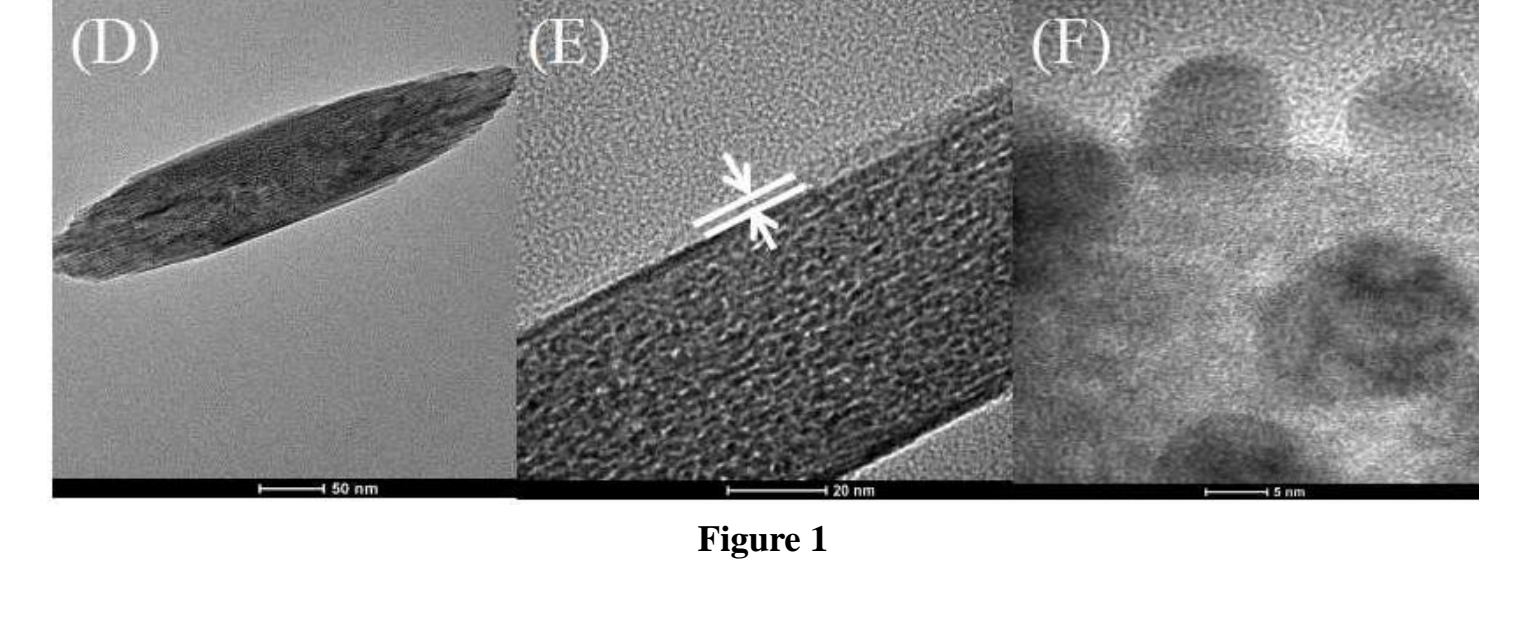

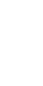
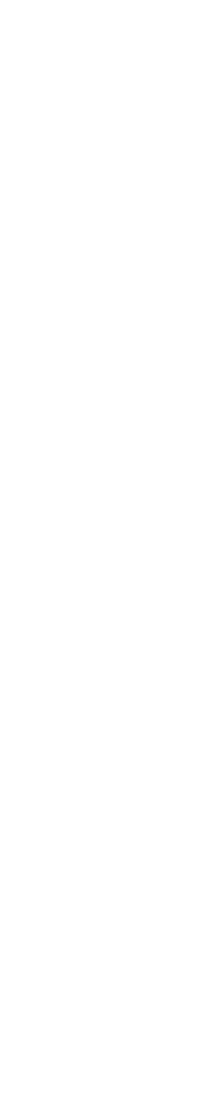
Figure 2
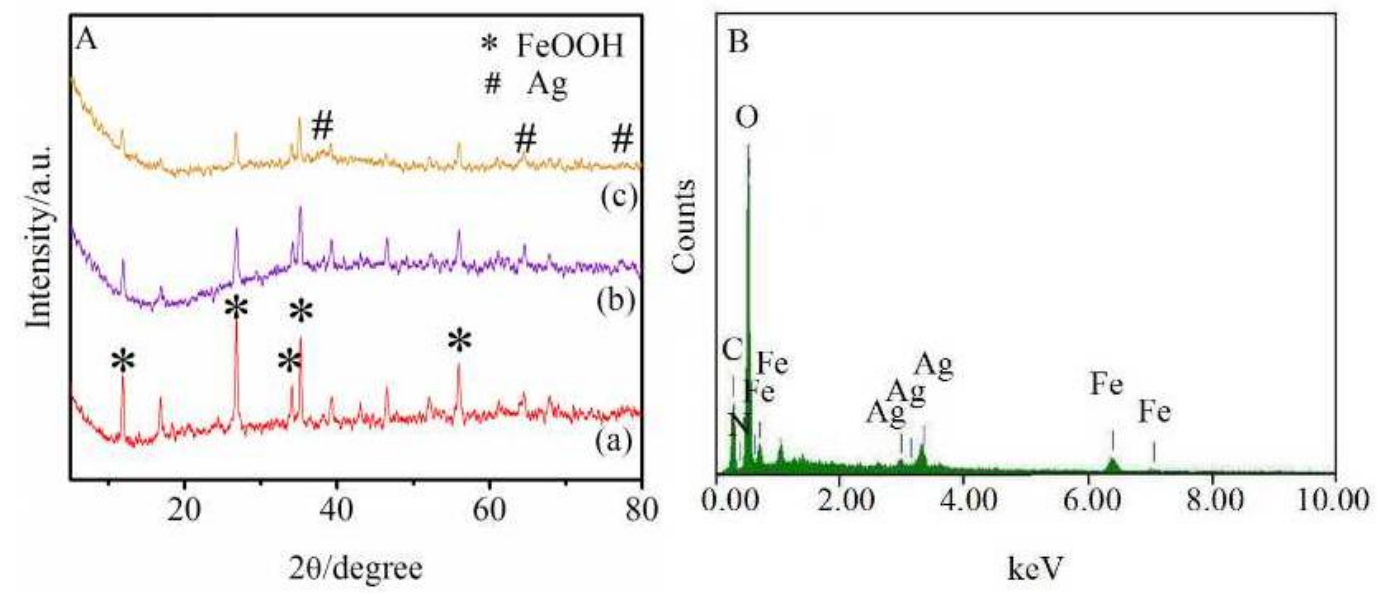

Figure 2

20/degree

$\mathrm{keV}$ 
Figure 3
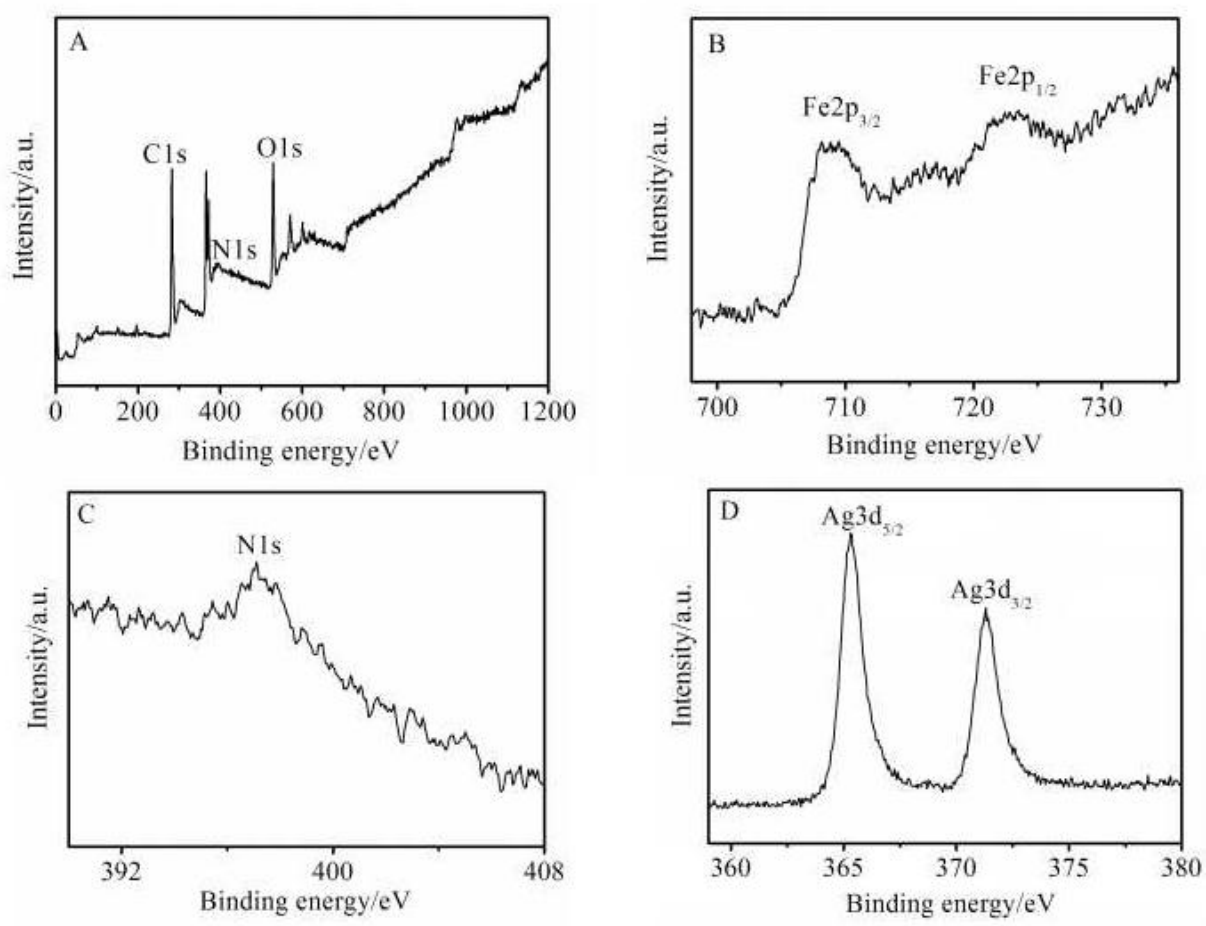

Figure 3 
Figure 4
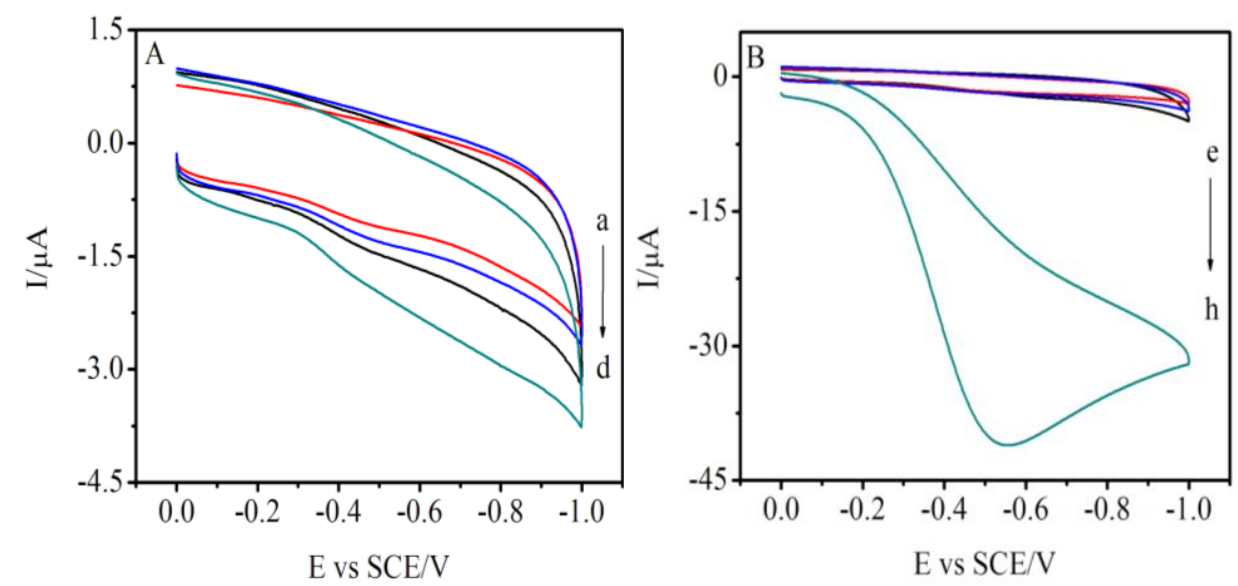

Figure 4 
Figure 5

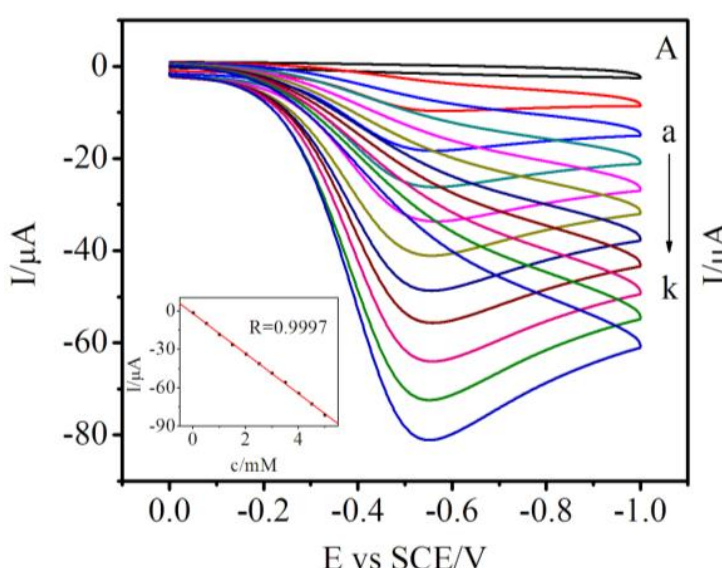

E vs SCE/V

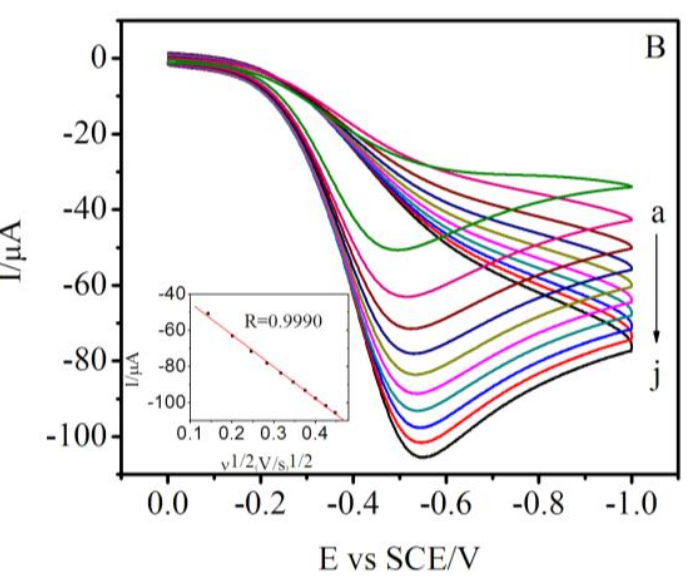

Figure 5 
Figure 6
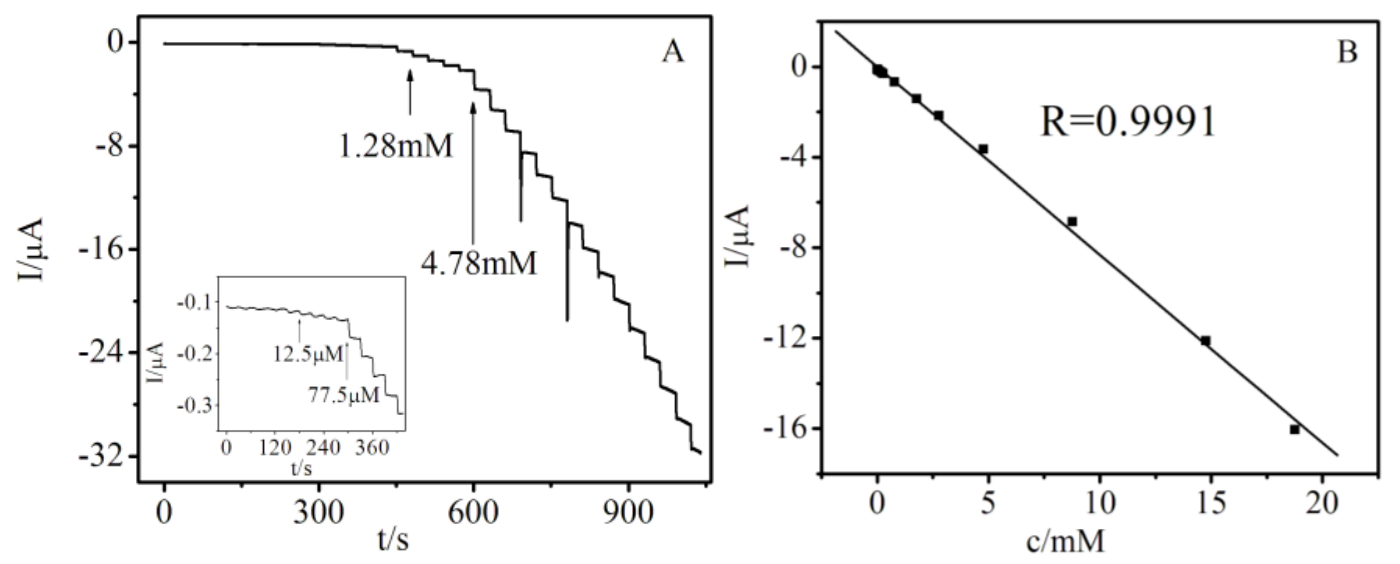

Figure 6 
Figure 7

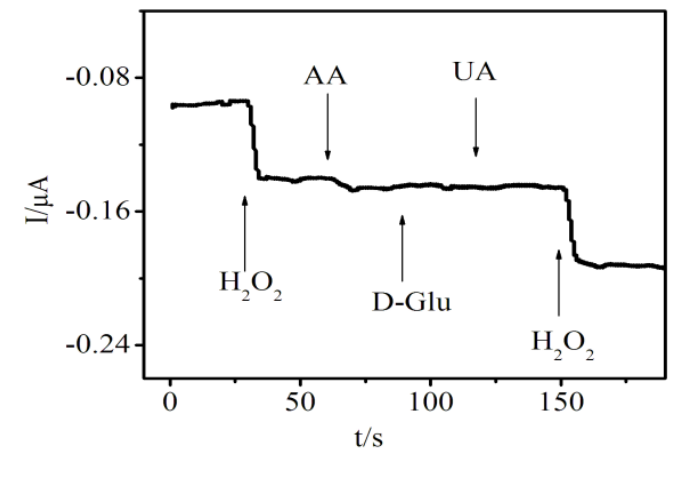

Fig

\section{Figure 7}

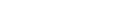

(2) 